\title{
Benefits of Implementing Group Work into the EFL Classroom
}

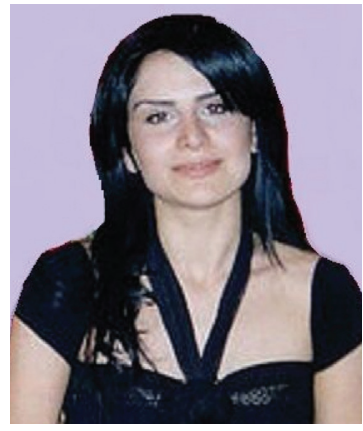

Syuzi Hovhannissyan

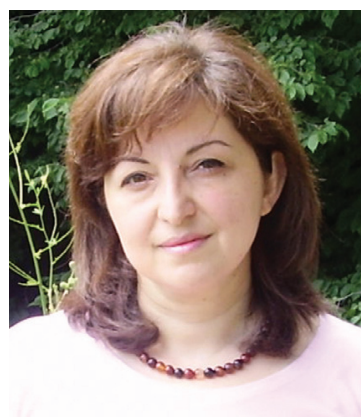

Lili Karapetyan

Croup work is an effective technique for teaching and

J learning and is a key factor to sustain interaction in a language classroom. Group work in the EFL classroom has largely been accepted as an effective strategy in the development of students' communicative proficiency in English (Chen \& Hird 2006). It has become an integral part of English teacher's repertoire of approaches and strategies.

Group work (also called cooperative learning, collaborative learning, collective learning, group study, etc.) covers a variety of techniques in which two or more students are assigned to do a single task together (Brown 2001). It developed as an active strategy with its proper characteristics and practical implications.

A characteristic proper to group work is that communication is established at two levels: the vertical level (communication between the teacher and the learners), and the horizontal level (communication between the learners themselves).

This results in intensive communication and interaction between the classroom members, leading to a rich source of feedback for both the teacher and the learners.

In general, the advantages of group work can be classified into three types: cognitive, psychological and social.

In terms of cognitive advantages learning in groups is a kind of training for logical and creative thinking and for the development of the learners' learning strategies and abilities as they are working collectively and co-operatively to achieve specific tasks. When students have to explain and negotiate their contributions to a group project, it assists them in developing and increasing their meta-cognitive awareness. That is, in "low risk" contexts they begin to realize what they know and what they have yet to learn or find out.

The psychological implications concern the affective involvement of the learners as group work facilitates the development of communication and interaction among the classroom members. This would enable the learner to know better his self and try to develop his personal characteristics by adopting positive ones such as the sense of responsibility, a positive self-image and confidence in himself and in other participants. This is because the learner would feel more at ease and less dependent on the teacher when he works collectively with his friends.

As far as the social implications of group work are concerned, the latter stimulates the learner's integration in the group, which can be a means for acknowledging and utilizing individual students' additional strengths and expertise. Through communication 
and interaction, group members gradually become familiar with each other (Harrison \& Carroll 1991). The quality of relationship with the other group members is a major factor in the overall success of the group, so it is important to spend time getting to their friends. Thus, it can foster the development of good social attitudes and moral values such as the spirit of co-operation and help, mutual respect, receptivity and openness to others, to their opinions and ideas.

One difficulty with group work is that you can't work as quickly as you can by yourself. Patience, communication skills and commitment are all required to make the most of the contributions of all group members. Consequently, effective group work requires each member to focus on the process rather than just the product.

In class activity students are involved to actively participate, cooperate, share experiences, work together, analyze, summarize and reflect on their activities. The teaching-learning process is more student oriented, while the role of the teacher is to be a facilitator. Doing the assignments in groups will create communicative positive atmosphere in which students are able to exchange their thoughts, ideas and learn to negotiate with one another. Vygotsky stated that students need an opportunity to express their verbal ability. By involving students to speak, they will internalize what they had told to be a thought and evaluate their weaknesses and strengths (Vygotsky 1978). In line with the above point of view, Vernon A. Magnesen claimed that people learned $90 \%$ from what they said and did. Piaget is also convinced that students learn through concrete experience by reflecting their experience. Working together in groups also gives students the opportunity to learn from and teach each other. Classroom research has shown that students often learn better form each other than they do from a teacher (Kelas 2008).

Studies have also shown that a group can be highly effective when individual members' goals are linked to the group goal (Martocchio \& Frink 1994).

Brown, Davis and Long show that students learn more and memorize better when they work in small groups, rather than when they work individually. In order to have successful peer-group work, students must have common understanding of the goal of the task and come to one conclusion: what they are willing to achieve (Brown 2001; Davis 1993; Long 1985).

There are three general types of group work: informal learning groups, formal learning groups and study teams. Informal groups are formed by just randomly clustering students within a single class period. Formal groups are established to fulfill a specific task with an outcome, such as writing a report or, for example, preparing a career paper, etc. To set up formal learning groups teachers are suggested to discuss and use the following steps: a) plan each stage of group work, b) explain the objectives of groups, c) make the group work relevant to the students' skills and abilities, d) divide the work equally among all group members. Study teams, unlike informal learning groups, are long term groups whose members remain the same through a whole term or so. Their role is to provide members with support, encouragement, and assistance in completing course assignments and requirements (Davis 1993). 


\section{Pedagogical Arguments for Group Work}

There are many pedagogical arguments for group work introduced by different authors. According to them group work may:

- Increase the language practice opportunities. Long and Corden argue that group work generates student talk; they get to talk more than they do during a whole class activity. Thus, the time for practising the new language increases (Long 1985; Corden 2001).

- Improve the quality of student talk. Because group is a natural setting for a conversation, students feel secure and out of public display, this way the quality of their talk improves, they do not have teachers "at hand" to correct them right away.

- Individualize instruction. As Long, Richards, Rodger and Davis argue, group work helps to assign individual students different assignments and responsibilities, in this way each of them will be responsible for their portion. So, having different skills and abilities students will get assignments which will be equivalent to their skills and abilities (Long 1985; Richards \& Rodgers 2001; Davis 1993).

- Provide a "positive affective climate" (Brown 2001). In small groups students feel more secure, even those students who talk rarely in the classroom get motivated to talk in small groups. Thus, small groups provide a more supportive climate to express oneself (Long 1985). In small groups students are less vulnerable and less criticized. Even not talkative students become active and cooperate with their peers (Brown 2001).

- Motivate learners. Dornyei and Long argue that group work motivates learners to speak freely. They highlight two aspects of group dynamics, i.e. group cohesiveness and group norms. The cohesive group is the one where all the students feel the strength of "we", they are happy to be a part of "we". This way they stick to each other, and the commitment to excellence is more obvious. These positive relations serve as keystones to motivate each other, to "pull each other along" and create an enjoyable atmosphere for themselves. On the other hand, if the group establishes effective norms for learning, group motivation increases greatly (Dornyei 2001; Long 1985).

However, methodologists are not unanimous as to how many participants a group should involve. Richards \& Rodgers and Davis claim that group size should not be too large, i.e. maximum five people should be engaged in one group. But they also state that it depends on the tasks the learners will carry out, as well as on the time limits they will have. Groups should be small in order to allow each student to express himself/herself. In this case they will also have more time to communicate (Richards \& Rodgers 2001; Davis 1993).

\section{Student Behavior in Small Groups}

A lot of research has been done to discover how students behave while learning in small groups. The research by Muller shows that children in autocratically led groups seem to be discontented, often aggressive and there is a lack of motivation. Whereas in 
democratically led groups they are far more productive and complete tasks successfully. Sometimes student behavior depends not only on their personalities but also who they are working with. In her study Muller shows empirical evidence of 6 groups working together; some groups were successful, while the others were not, mostly because they couldn't find common understanding of the task (Muller 2001).

Group work is a keystone for sustaining interaction in a big classroom and for motivating learners to practice their language. However equal time should be provided to the students to participate and cooperate in small group discussions. This way they all get turns to share their ideas with each other as well as to the audience they will be exposed to later. Group work promotes learners to be responsible, it encourages taking risks and helps to overcome difficulties with an impressive ease.

\section{Implementing Group Work into the Armenian Educational Setting}

Despite the above mentioned benefits of group work it is hardly ever used in the Armenian formal educational setting where the whole studying process is teacher-centered rather than learning-centered. The majority of learners undergo the process of learning through traditional educational methods in which they are not likely to experience a student-centered learning environment in terms of group work. Most of the language teaching and learning processes in classrooms do not develop contextual communication atmosphere whereas students cannot use contextually fixed expressions in communicating with one another. In real classroom situations teachers just ask students to arrange a dialogue, memorize the dialogue, then perform it. On the other hand, teaching and learning activity is often disturbed by several factors i.e. the thought that English is difficult to learn, has complex grammar and strange pronunciation, etc. These make students speak less. In learning activity, students seldom get an opportunity to express ideas, opinions, and thoughts, the activities often seem monotonous, there is less interaction between teachers and students on the one hand, and students to students on the other hand. Whereas, as Kelas states "teaching English as a foreign language should be directed to be a lively communicative process" (Kelas 2008).

We strongly believe that implementing group work into the Armenian educational establishments will stimulate effective learning and teaching, active involvement of learners who will find more opportunities to express themselves and feel less anxious and more capable to communicate with the teacher and even with each other in the group. Group work will provide Armenian EFL students with opportunities for developing skills like organization, negotiation, team work and co-operation which Armenian students very often lack.

\section{References:}

1. Brown, H. D. (2001) Teaching by Principles: An Interactive Approach to Language Pedagogy. NY: Pearson Education. 
2. Chen, B., Hird, B. (2006) Group Work in the EFL Classroom in China: A Closer Look. // RELC Journal, Vol. 37(1). www.relc.org.

3. Corden, R. (2001) Group Discussion and the Importance of a Shared Perspective: Learning from Collaborative Research. RELC Journal, 1(3). www.relc.org.

4. Davis, B. G. (1993) Collaborative Learning: Group Work and Study Teams. Retrieved October 23, 2009, from http://teaching.berkeley.edu/bgd/collaborative.html.

5. Dornyei, Z. (2001) Motivational Strategies in the Language Classroom. UK: Cambridge University Press.

6. Harrison and Carrol, (1991) The Dynamics of Cultural Influence Networks. // Administrative Science Quarterly (43). California: California University Press.

7. Long, M. H. (1985) Group Work, Interlanguage Talk, and Second Language Acquisition. TESOL Quarterly, 19(2). California: California University Press.

8. Martocchio, P. (1994) A Review of the Influence of Group Goals on Group Performance. // Academy of Management Journal, Vol. 37(5). Texas: Texas University Press.

9. Muller, A., Fleming, T. (2001) Cooperative Learning: Listening to How Children Work at School. // Journal of Educational Research, 94(5). Penssylvania: Penssylvania State University.

10. Richards, J.C., Rodgers, T.S. (2001) Approaches and Methods in Language Teaching. Cambridge: Cambridge University Press.

11. Vygotsky, L.S. (1978) Mind in Society: The Development of Higher Psychological Processes. Cambridge, MA: Harvard University Press.

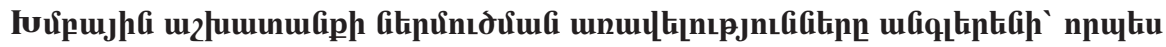

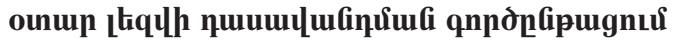

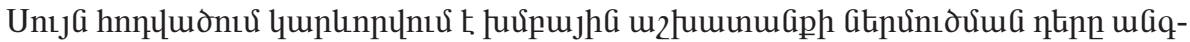

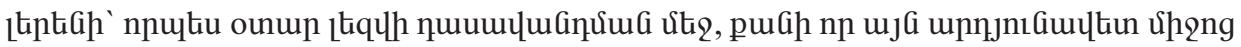

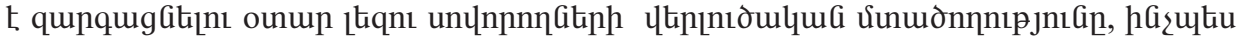

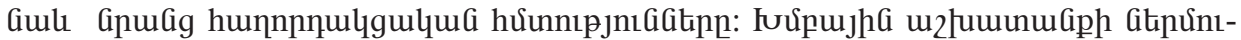

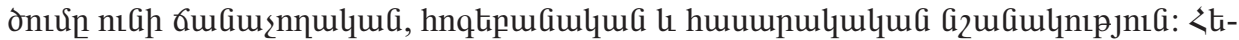

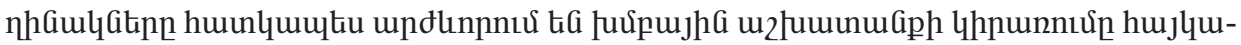

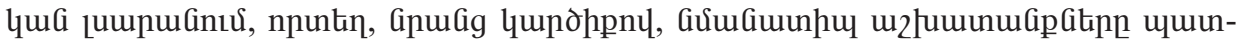

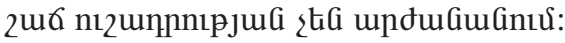

